\title{
Article
}

Arq Neuropsiquiatr 2011;69(5):790-798

\section{A topographic study on the evaluation of speech and language in the acute phase of a first stroke}

\author{
Fabricio Ferreira de Oliveira', Benito Pereira Damasceno²
}

\begin{abstract}
Evaluation of speech and language may help in localization of site and extension of brain lesions, particularly in the absence of other neurological signs or radiologically defined injuries. Objective: To verify what language tasks are best correlated to which brain regions, in order to develop a test for neurologists in emergency settings. Method: Thirty-seven adult first-stroke patients were submitted to cognitive and language tests, and then paired with thirty-seven healthy controls. Patients underwent CT and/or MRI for topographic correlation with test results $(p<0.05)$. Results: All tests were able to distinguish patients from controls, but only word/sentence repetition, naming, ideomotor praxis and, non-significantly, comprehension and counting 1-20 predicted left hemisphere lesions. Repetition was related to perisylvian structures, comprehension to the posterior portion of the middle cerebral artery territory, and fluency to frontal lesions, while naming was accurate only for lesion side. Conclusion: Language and cognitive tasks can help in the localization of acute stroke lesions.
\end{abstract}

Key words: linguistics, aphasia, apraxias, stroke, brain infarction, language, speech, disability evaluation.

Um estudo topográfico da avaliação de fala e linguagem na fase aguda de um primeiro infarto cerebral

\section{RESUMO}

Avaliação de fala e linguagem pode ajudar na localização do sítio e da extensão de lesões cerebrais, especialmente quando ausentes outros sinais neurológicos ou radiológicos. Objetivo: Verificar quais tarefas linguísticas se correlacionam melhor com quais regiões cerebrais, a fim de desenvolver um teste para uso pelos neurologistas em emergências. Método: 37 pacientes e 37 controles pareados passaram por avaliação linguísticocognitiva. Pacientes foram submetidos a TC e/ou RM para correlação topográfica com os resultados da avaliação $(p<0,05)$. Resultados: Todos os testes diferenciaram pacientes de controles, mas apenas os de repetição de palavras/sentenças, nomeação, praxia ideomotora e, de forma não-significativa, compreensão e contagem 1-20 puderam predizer lesões no hemisfério esquerdo. Os testes de repetição estavam relacionados com estruturas perisylvianas, compreensão com a porção posterior do território da artéria cerebral média, e fluência com regiões frontais, enquanto os de nomeação localizavam apenas o lado das lesões. Conclusão: Testes linguístico-cognitivos podem ajudar a localizar infartos cerebrais agudos.

Palavras-Chave: linguística, afasia, apraxias, acidente cerebral vascular, infarto encefálico, linguagem, fala, avaliação da deficiência.

This study was supported by CAPES (Coordenação de Aperfeiçoamento de Pessoal de Nível Superior)

Conflict of interest

The authors report no conflict of interest

Stroke is the leading cause of handicap in developed countries, and the most common neurological reason for inpatient admission. Throughout the brief timewindow for effective therapeutic reperfusion in acute ischemic stroke, evaluation 
of speech and language may help neurologists to localize brain injury site and extension even in the absence of other neurological signs, and still in the absence of radiologically defined lesions ${ }^{1,2}$.

Classic aphasias have been correlated to specific brain regions and regarded as vascular syndromes ${ }^{3}$. Several tests are available for evaluation of speech and language, but they are more suitable for psychological assessments, taking around 30 minutes or more for completion ${ }^{4}$. Therefore, they are not useful for emergency neurological examinations. Other complicating factors for assessment of speech and language in the acute stroke phase are, for instance, patient cooperation, the required length for a complete evaluation, and time of stroke evolution. Increasing experience and specific training for examination of speech and language may lead to a more precise diagnosis in time ${ }^{5}$.

The aim of this study was to verify what language tasks are more consistently correlated to which brain regions, in order to contribute to the development of a quick and accurate instrument for evaluation of speech and language to be used by neurologists in emergency settings, particularly when stroke localization by neuroimaging is incomplete or not possible.

\section{METHOD}

This is a blind, prospective, non-randomized study, in which patients were evaluated for speech and language within 72 hours from a single first-ever ischemic brain injury. Recruitment was carried out from May 2007 to April 2008 at the Hospital das Clínicas/UNICAMP, with the enrolment of all consecutive patients admitted to the Emergency Unit who presented the following additional characteristics: adults over 18 years-old, any educational level, not comatose, no evidence of previous strokes or other brain diseases, no other incapacitating or medically unstable conditions, no history of alcoholism or chronic occupational exposure to neurotoxic substances. Subjects were paired with healthy controls according to age ( \pm 5 years) and educational level ( \pm 2 years). Cerebral computed tomography (CT) and/or 2.0 tesla magnetic resonance imaging (MRI) were performed for topographic correlation between speech and language assessment results and the brain injury site, both in the acute and the chronic phases (surviving patients would be submitted to MRI or CT at an average of 3 months post-stroke). Preference was given to the MRI, except in cases of patients who were claustrophobic or had metallic devices in their bodies; in such situations, a CT had to be repeated in the chronic phase. All radiological exams were evaluated by two neurologists and by at least one radiologist. Subjects would be excluded from the study in case more than one defined brain lesion hap- pened to be found, or if the injury was restricted to areas of the central nervous system other than the brain itself. All survivors were followed for a period of 3-18 months after the acute stroke.

Definition of stroke followed the WHO MONICA criteria ${ }^{6}$ : rapidly developing signs of focal or global disturbance of cerebral function, lasting more than 24 hours or leading to death, with no apparent cause other than vascular.

A neurologist who was trained on the assessment items (FFO) conducted the neurological evaluation. The crucial aspects of the language testing were recorded in colour with a digital camera. In case of uncertainties regarding the diagnosis of aphasic syndromes, the authors would agree on a consensus when reviewing the evaluation.

The examiner was blind to the neuroimaging localization diagnosis during the assessment ${ }^{7}$, which consisted on a short medical interview with a complete neurological exam including visual acuity and hearing evaluation (listening to finger-scratching with closed eyes, in each ear at once), and also the following cognitive and linguistic tasks:

[1] Attention was examined by means of the " $\mathrm{A}$ " Random Letter Test $^{8}$, in which patients had to tap the unimpaired hand on the desk immediately after hearing the letter " $\mathrm{A}$ " (scoring was in accordance with the number of errors, which could be omission, perseveration, or tapping for another letter);

[2] Hand dominance was assessed according to a 5-point scale of the Edinburgh Inventory';

[3] Visual perception was tested by showing $10 \mathrm{ab}$ stract figures (modified from Jones-Gotman et al. ${ }^{10}$, 1997), each of them displayed for 10 seconds, soon after which the patients would have to point to each among 4 other figures (scored as hit-or-miss, maximum score $=10)$;

[4] Evaluation of ideomotor praxis - subjects were asked to perform five separate tasks: to put the tongue between the upper lip and the teeth, to whistle, to wave goodbye, and to pretend to light and blow out the fire of a match with and without a real match (scoring 1 point for each correct action);

[5] Evaluation of constructional praxis - to copy with matches two match-made figures, each task scoring 1 (correct) or 0 (wrong): the figure of an equilateral triangle having an adjacent line going 60 degrees from one of the vertices (4 matches were given to the subject); and the figure of two pentagons joined by one of their sides (9 matches were given);

[6] Evaluation of language and speech functions comprised:

- Spontaneous narrative speech in answer to the in- 
quiries "How are you??, “Tell me about your work!", “Tell me about your everyday activities!", recording the presence of mutism, poverty of speech, latency for response, coherence of response, impaired comprehension, phonemic or semantic paraphasias, neologisms, perseveration or echolalia, and grammatical errors (score was 1 if any of these symptoms present, or 0 if absent);

- Evaluation of fluency by recording the presence (score 1) or absence (0) of non-fluent speech manifested as increased latency or effort to respond, phono-articulatory difficulties, phonetic mistakes and word-finding difficulty;

- Auditory perception of phonemes was tested by repetition of 11 different letters or phonemes (scoring 1 point for each correct repetition up to a maximum of 11 points) ${ }^{11}$ : O, A, M, P, B, D, T, L, N, G (guê), Q ${ }^{11}$;

- Study of comprehension with three simple yesor-no questions ("Is this place your home?", "Is the ant bigger than the elephant?", "Is your father's brother your uncle?") and three commands ("Show me your tongue!", "Raise your arms!", "Put your hand on my nose!"), with a maximum score of 6 ;

- Repetition of four words: house, banana, forest, metalworker, and three sentences: it is not raining today, the moon glitters in the sky, little and often the hen fills its crop, scoring 1 point for each word or sentence correctly repeated;

- Naming six objects (button, coin, clock, pen, match, nail), scoring 1 point for each;

- Study of automatic speech by asking the subject to count from 1 to 20, to mention the 7 days of the week, and to fully sing the song "Happy birthday...", scoring 1 for each correct task.

Results of language tests were inserted into a classification table (Table 1$)^{3,12}$. Aphasia is defined as loss of linguistic or communicative ability, characterized by difficulty to understand and/or produce words; phonemic distortion or exchange of words (phonemic or semantic paraphasias, respectively); difficulty to name objects (anomia) or to recall words during conversation ${ }^{13}$. Reading and writing are usually affected, while phonoarticulatory function and consciousness are relatively preserved. In this study, dysarthria was clinically distinguished from apraxia of speech in that it is often accompanied by slowing or paresis of tongue movements, dysphagia, and production of consistent phono-articulatory errors, while apraxia of speech may occur without significant weakness, with preservation of the involuntary and automatic movements of chewing and swallowing, and production of inconsistent articulatory errors, sometimes with well articulated and fluent parts of sentences $^{3,14}$.

Size of infarct was classified as large (more than 1.5 $\mathrm{cm}$ in diameter on CT or MRI at any plane) or small (less than $1.5 \mathrm{~cm}$ in diameter on CT or MRI at all planes), in accordance with the TOAST classification ${ }^{15}$. Parietal lesions were not accounted for in the category of injured lobes because they consisted on a small group of nonaphasics - only 3 patients. We considered as subcortical lesions those radiologically confirmed injuries that included the periventricular white matter, thalamus, internal capsule, globus pallidus, caudate nucleus or lenticular nucleus ${ }^{16}$.

Chi-square or Fisher's exact test were used for comparisons of categorical variables. For continuous measures, we applied the Mann-Whitney test and ANOVA, followed by Tukey's test. Multiple logistic regression analysis was used to identify variables that could discriminate between lesion sides (left or right). Significance was set at $\mathrm{p}<0.05$.

This study was approved by the Ethics Committee of the Faculty of Medical Sciences, University of Campinas / UNICAMP (CAAE 2081.0.000.146-06), on March 2007. All patients or their representatives signed the informed consent form before the evaluation (we secured the assent of the next-of-kin if the patient was unable to write or had severe comprehension impairment). All the approached subjects agreed to participate.

\section{RESULTS}

We included 37 patients (22 male, 15 female) and 37 matched controls ( 23 male, 14 female), $\mathrm{p}=0.818$. Mean age was $63.96 \pm 11.3$ years for patients and $62.29 \pm 11.4$ years for controls $(\mathrm{p}=0.6379)$. Mean educational level was $4.8 \pm 4.1$ years for patients and $5.1 \pm 4.0$ years for controls $(\mathrm{p}=0.4162)$. Among all patients, $3(8.1 \%)$ were illiterate, and other $25(67.6 \%)$ had at most 4 years of schooling.

The classifications of language and speech disorders according to the results of the test battery are showed in Table 1. Ranging scores from 10 to 50 in the Edinburgh Inventory ${ }^{9}$, patients numbered as 1 (score of 42) and 35 (score of 46) in Table 2 were considered lefthanded; among controls, only the control of patient number 35 was left-handed (score of 46). All other patients had scores between 10 and 18, while other controls had scores between 10 and 23, and were considered right-handed.

Thirty-three (89.2\%) patients had aphasia or dysarthria in the acute phase, while $4(10.8 \%)$ showed no speech or language disabilities. As shown in Table 2, $35.2 \%$ of these 33 patients had lone cortical dysarthria, 29.7\% had global aphasia, 8.1\% had Broca's aphasia, 5.4\% had Wernicke's aphasia, $8.1 \%$ had transcortical aphasias and $2.7 \%$ had thalamic aphasia. Nine $(81.8 \%)$ of the 11 global aphasia patients were mute in the acute stroke phase $(\mathrm{p}<0.001)$. Among the 33 patients with speech or 


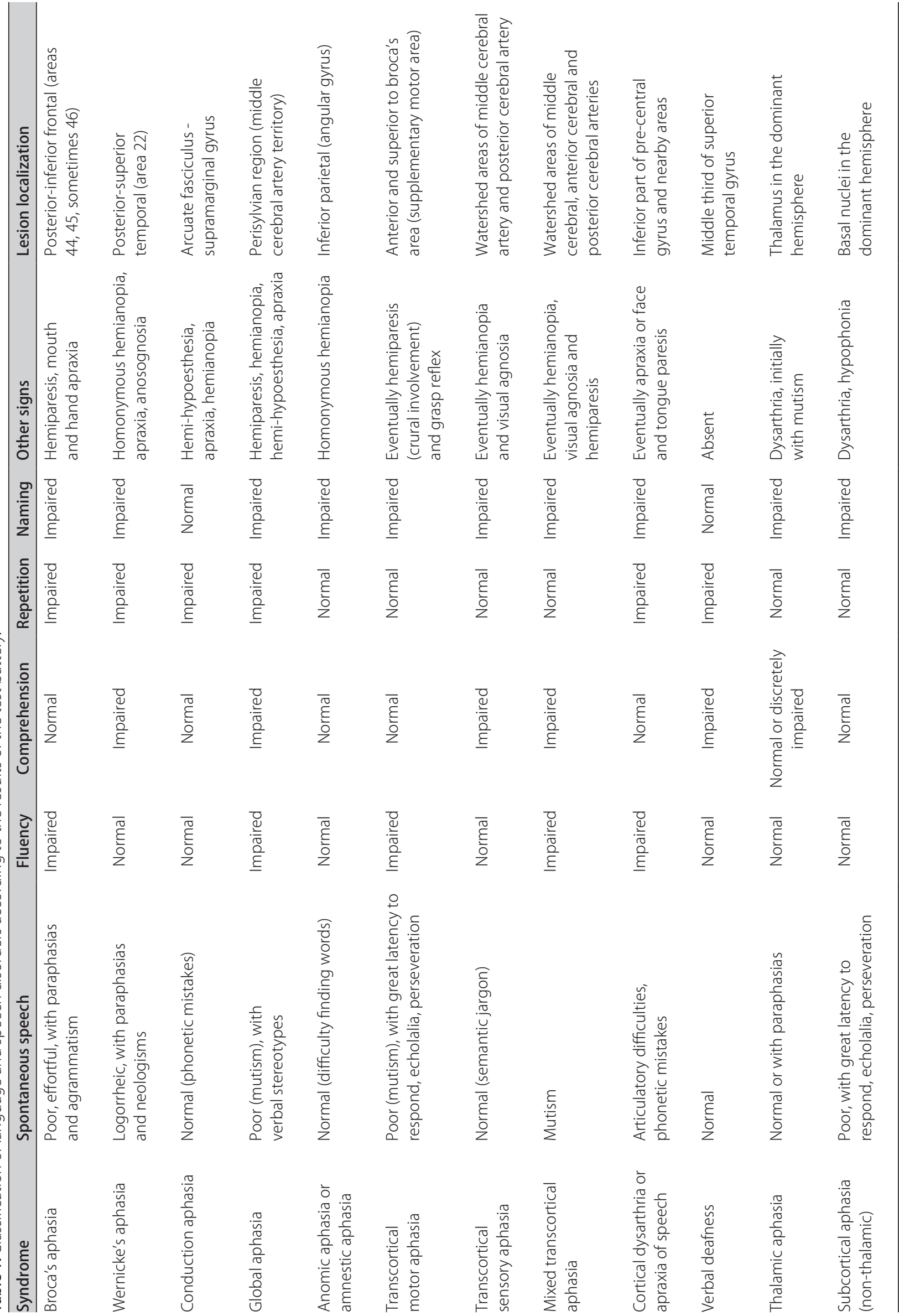


Table 2. Demographic and clinical characteristics of the 37 stroke patients.

\begin{tabular}{|c|c|c|c|c|c|c|}
\hline Patient & Gender & Age & $\begin{array}{l}\text { Schooling } \\
\text { (yrs) }\end{array}$ & Lesion aspect (CT and/or MRI) & TOAST & Neurological exam \\
\hline \multicolumn{7}{|c|}{ Lone cortical dysarthria $(n=13)$} \\
\hline 01 & M & 61.65 & 4 & CT: small subcortical left capsule-nuclear & U & Hemianopia, hemiparesis, hypoesthesia \\
\hline 02 & $\mathrm{~F}$ & 56.38 & 3 & CT: small subcortical left capsule-nuclear & S & Hemiparesis, hypoesthesia \\
\hline 03 & $\mathrm{~F}$ & 65.50 & 0 & CT+MRI: small subcortical left capsule-nuclear & S & Hemiparesis \\
\hline 04 & $\mathrm{~F}$ & 67.84 & 11 & CT+MRI: large subcortical left capsule-nuclear & S & Hemiparesis \\
\hline 05 & $\mathrm{~F}$ & 73.31 & 4 & CT+MRI: large subcortical left capsule-nuclear & $S$ & Hemiparesis, hypoesthesia \\
\hline 06 & $\mathrm{~F}$ & 39.34 & 4 & $\mathrm{CT}$ : large cortical-subcortical right MCA territory & U & Neglect, hemianopia, hemiparesis, hypoesthesia \\
\hline 07 & M & 65.07 & 0 & CT: small subcortical right capsule-nuclear & $U$ & Neglect, hemiparesis, hypoesthesia \\
\hline 08 & M & 55.65 & 8 & CT: large cortical-subcortical right temporal-parietal & L & Neglect, hemianopia, hemiparesis \\
\hline 09 & M & 73.97 & 3 & $\mathrm{CT}+\mathrm{MRI}$ : large cortical-subcortical right MCA territory & C & Neglect, hemianopia, hemiparesis, hypoesthesia \\
\hline 10 & M & 58.72 & 2 & $\mathrm{CT}+\mathrm{MRI}$ : large cortical-subcortical right MCA territory & $U$ & Neglect, hemianopia, hemiparesis, hypoesthesia \\
\hline 11 & $\mathrm{~F}$ & 61.19 & 2 & $\mathrm{CT}$ : large cortical-subcortical right MCA territory & $u$ & Neglect, hemianopia, hemiparesis \\
\hline 12 & M & 72.42 & 0 & $\mathrm{CT}$ : large subcortical right capsule-nuclear & $U$ & Neglect, hemianopia, hemiparesis, hypoesthesia \\
\hline 13 & M & 57.35 & 3 & CT: large cortical-subcortical left frontal & C & Hemiparesis \\
\hline \multicolumn{7}{|c|}{ Global aphasia $(n=11)$} \\
\hline 14 & $\mathrm{~F}$ & 52.17 & 4 & CT+MRI: large cortical-subcortical left frontal & L & Hemianopia, hemiparesis \\
\hline 15 & M & 53.35 & 7 & CT+MRI: large cortical-subcortical left MCA territory & C & Hemianopia \\
\hline 16 & M & 57.61 & 8 & CT+MRI: large cortical-subcortical left frontal & L & Hemiparesis \\
\hline 17 & $\mathrm{~F}$ & 51.31 & 16 & CT+MRI: large cortical-subcortical left MCA territory & U & Hemianopia, hemiparesis, hypoesthesia \\
\hline 18 & M & 46.50 & 8 & CT+MRI: large cortical left MCA territory & U & Hemianopia, hemiparesis, hypoesthesia \\
\hline 19 & M & 80.23 & 4 & CT+MRI: large cortical-subcortical left MCA territory & C & Hemianopia, hemiparesis \\
\hline 20 & $\mathrm{~F}$ & 85.75 & 2 & CT: large cortical-subcortical left MCA territory & C & Hemianopia, hemiparesis \\
\hline 21 & M & 58.92 & 4 & CT: large cortical-subcortical left MCA territory & $U$ & Hemianopia, hemiparesis \\
\hline 22 & M & 59.08 & 16 & CT: large cortical-subcortical left MCA territory & C & Hemiparesis, hypoesthesia \\
\hline 23 & M & 60.38 & 4 & CT: large cortical-subcortical left MCA territory & U & Hemianopia, hemiparesis, hypoesthesia \\
\hline 24 & M & 85.89 & 1 & CT: large cortical-subcortical left MCA territory & C & Hemianopia, hemiparesis \\
\hline \multicolumn{7}{|c|}{ Broca's aphasia $(n=3)$} \\
\hline 25 & $\mathrm{~F}$ & 46.88 & 2 & CT+MRI: small cortical-subcortical left frontal & C & Hemianopia, hemiparesis \\
\hline 26 & M & 70.00 & 4 & CT: large cortical left frontal & C & \\
\hline 27 & M & 79.19 & 1 & CT+MRI: large cortical-subcortical left frontal & U & Hemianopia \\
\hline \multicolumn{7}{|c|}{ Wernicke's aphasia $(n=2)$} \\
\hline 28 & $\mathrm{~F}$ & 71.264 & & $\begin{array}{l}\mathrm{CT}+\mathrm{MRI} \text { : small cortical-subcortical } \\
\text { left temporal-parietal }\end{array}$ & C & Hemianopia \\
\hline 29 & M & 58.6716 & & $\mathrm{CT}$ : small cortical left temporal-parietal & C & \\
\hline \multicolumn{7}{|c|}{ Mixed transcortical aphasia $(n=2)$} \\
\hline 30 & M & 74.143 & & CT+MRI: large subcortical left temporal-parietal & L & Hemiparesis \\
\hline 31 & $\mathrm{~F}$ & 75.494 & & CT: large cortical-subcortical left MCA territory & U & Hemiparesis \\
\hline \multicolumn{7}{|c|}{ Transcortical motor aphasia $(n=1)$} \\
\hline 32 & $\mathrm{~F}$ & 69.897 & & $\mathrm{CT}$ : large subcortical left temporal-parietal & U & Hemianopia, hemiparesis \\
\hline \multicolumn{7}{|c|}{ Thalamic aphasia $(n=1)$} \\
\hline 33 & $\mathrm{~F}$ & 80.034 & & $\begin{array}{l}C T \text { : small subcortical left temporal- } \\
\text { parietal (capsule-thalamic) }\end{array}$ & S & Hemiparesis, hypoesthesia \\
\hline \multicolumn{7}{|c|}{ No aphasia or dysarthria $(n=4)$} \\
\hline 34 & $\mathrm{~F}$ & 53.154 & & $\mathrm{CT}$ : small subcortical right parietal & S & Hemianopia, hemiparesis, hypoesthesia \\
\hline 35 & M & 52.874 & & CT+MRI: small subcortical left parietal & S & Hemiparesis, hypoesthesia \\
\hline 36 & M & 63.324 & & CT+MRI: small subcortical left parietal & U & Hemianopia, hemiparesis \\
\hline 37 & M & 71.262 & & CT: large cortical-subcortical right MCA territory & U & Neglect, hemianopia, hemiparesis, hypoesthesia \\
\hline
\end{tabular}

MCA: middle cerebral artery; F: female; M: male; large: more than $1.5 \mathrm{~cm}$ in diameter on CT or 2T-MRI at any plane; small: less than $1.5 \mathrm{~cm}$ in diameter on CT or 2T-MRI at all planes; C: cardioembolism; L: large-artery atherosclerosis; S: small-artery occlusion; O: other determined etiology; U: undetermined etiology. 
Table 3. Comparisons between patients and controls in cognitive and language tests.

\begin{tabular}{|c|c|c|c|c|}
\hline Variable & Maximum test score & Patients & Controls & $\mathrm{p}$-value \\
\hline$n$ & - & $37(100 \%)$ & $37(100 \%)$ & - \\
\hline Attention: no scored mistakes & - & $25(67.57 \%)$ & $37(100 \%)$ & $0.0002^{*}$ \\
\hline Vigilance test: mean errors $\pm S D$ & 20 & $11.5 \pm 8.4$ & $0.5 \pm 1.1$ & $<0.0001^{* *}$ \\
\hline Right-Handedness (n): the Edinburgh Inventory & - & 35 (94.59\%) & $36(97.30 \%)$ & $1,0000^{* * *}$ \\
\hline Visual perception of abstract designs: mean \pm SD & 10 & $3.4 \pm 3.3$ & $9.3 \pm 0.7$ & $<0.0001^{* *}$ \\
\hline Auditory perception of phonemes: mean $\pm S D$ & 11 & $6.6 \pm 4.4$ & $10.6 \pm 0.8$ & $<0.0001^{* *}$ \\
\hline Spontaneous speech $(\mathrm{n})^{\dagger}$ & - & $9(24.32 \%)$ & $37(100 \%)$ & $<0.0001^{*}$ \\
\hline Disturbances in fluency (n) & - & $33(89.19 \%)$ & $0(0 \%)$ & $0.0002^{*}$ \\
\hline Comprehension tests: mean $\pm \mathrm{SD}$ & 6 & $3.8 \pm 2.5$ & $5.8 \pm 0.4$ & $<0.0001^{* *}$ \\
\hline Word repetition tests: mean $\pm S D$ & 4 & $2.4 \pm 1.9$ & $4.0 \pm 0.0$ & $<0.0001^{* *}$ \\
\hline Sentence repetition tests: mean $\pm S D$ & 3 & $1.6 \pm 1.5$ & $3.0 \pm 0.2$ & $<0.0001^{* *}$ \\
\hline Naming tests: mean $\pm S D$ & 6 & $3.2 \pm 2.7$ & $5.9 \pm 0.3$ & $<0.0001^{* *}$ \\
\hline Counting from 1 to $20^{+}$ & - & $19(51.35 \%)$ & $37(100 \%)$ & $<0.0001^{*}$ \\
\hline Mentioning the 7 weekdays ${ }^{+}$ & - & $20(54.05 \%)$ & $35(94.59 \%)$ & $<0.0001^{*}$ \\
\hline Singing ${ }^{+}$ & - & $18(48.65 \%)$ & $35(94.59 \%)$ & $<0.0001^{*}$ \\
\hline Phono-articulatory function ${ }^{+}$ & - & $21(56.76 \%)$ & $37(100 \%)$ & $<0.0001^{*}$ \\
\hline Ideomotor praxis tests: mean $\pm \mathrm{SD}$ & 5 & $2.8 \pm 2.0$ & $4.8 \pm 0.4$ & $<0.0001^{* *}$ \\
\hline Constructional praxis test - 4 matches ${ }^{\dagger}$ & - & $13(35.14 \%)$ & $29(78.38 \%)$ & $0.0002^{*}$ \\
\hline Constructional praxis test - 9 matches $^{+}$ & - & $9(24.32 \%)$ & $31(83.78 \%)$ & $<0.0001^{*}$ \\
\hline
\end{tabular}

SD: standard deviation; ${ }^{*}$ chi-square test; ${ }^{* *}$ Mann-Whitney test; ${ }^{* * *}{ }^{*}$ Fisher's exact test; ${ }^{\dagger}$ Number of subjects performing correctly.

language impairment, 7 (21.2\%) had right hemisphere lesions (presenting dysarthria without aphasia) and 26 (78.8\%) had left hemisphere lesions.

Among the 33 patients with aphasia or dysarthria (Table 2), there were $5(15.2 \%)$ with aphasic syndromes whose lesions deviated from the classic clinical-anatomic correlations shown in Table 1 (patients numbered as $14,16,30,31,32$ ). Patients performed inferior to controls on all cognitive and language tests $(\mathrm{p}<0.001)$, according to Table 3 . Only four tests were able to discriminate between brain injury sides: word repetition tests $(p=0.0062)$, sentence repetition tests $(p=0.0039)$, naming tests $(\mathrm{p}=0.0453)$, and ideomotor praxis tests $(\mathrm{p}=0.0293)$. Marginally significant results for discrimination between lesions to either hemisphere were found in regard to the comprehension tests $(\mathrm{p}=0.0556)$ and to counting from 1 to 20 (11 of 28 left hemisphere injured patients scored no mistakes, against 8 of 9 right hemisphere injured ones; $\mathrm{p}=0.0625)$. All other evaluated parameters were nonsignificant for discrimination between injured cerebral hemispheres.

Table 4 establishes the statistical value of comparisons between test scores, age and education, and the brain injury topography for stroke patients (the 4 patients without aphasia or dysarthria were excluded, there- fore we only considered 33 patients for this analysis).

Stepwise multiple logistic regression analysis showed that the sentence repetition tests were able to discriminate between lesion sides in favor of the right hemisphere when scores were high, both when the data of all variables were included (OR=14.093, 95\% CI 2.59-76.43, $\mathrm{p}=0.0022$, accuracy $93.3 \%$ ) and when vigilance tests, handedness, visual and phoneme perception tests were excluded (OR=3.647, 95\% CI 1.51-8.81, $\mathrm{p}=0.004$, accuracy 86.7\%).

The 33 patients with aphasia or dysarthria were classified in four lesion groups, which were similar in regard to age and education: frontal, temporal-parietal, capsule-nuclear, and whole middle cerebral artery (MCA) territory. Statistical analysis with ANOVA followed by Tukey's test showed that repetition of words and sentences was affected mainly by frontal and whole MCA territory lesions, and also by temporal-parietal lesions in lesser degree. Whole MCA territory was the lesion site most frequently associated to disturbances of spontaneous speech, comprehension, naming, sentence repetition, ideomotor and constructional praxis. These linguistic-cognitive functions were less affected by capsule-nuclear lesions which, along with temporal-parietal lesions, constituted the main cause of phono-articulatory difficulties and errors. 
Table 4. Comparisons between evaluated parameters of patients and brain injury topography.

\begin{tabular}{|c|c|c|c|c|c|c|}
\hline Variable & $\begin{array}{l}\text { Maximum } \\
\text { test score }\end{array}$ & $\begin{array}{l}\text { Frontal group } \\
\qquad(n=6)\end{array}$ & $\begin{array}{l}\text { Temporal- } \\
\text { Parietal group } \\
\quad(n=5)\end{array}$ & $\begin{array}{c}\text { Whole MCA } \\
\text { territory group } \\
(n=14)\end{array}$ & $\begin{array}{c}\text { Capsule- } \\
\text { nuclear group } \\
(\mathrm{n}=8)\end{array}$ & p-value \\
\hline Age (years; mean $\pm S D$ ) & - & $60.8 \pm 13.5$ & $70.4 \pm 8.1$ & $63.6 \pm 14.0$ & $63.4 \pm 6.7$ & $0.5007^{(1)}$ \\
\hline Education (years; mean $\pm S D$ ) & - & $3.8 \pm 2.7$ & $6.8 \pm 5.4$ & $5.3 \pm 4.7$ & $3.7 \pm 3.8$ & $0.5980^{(1)}$ \\
\hline Vigilance (errors; mean $\pm S D$ ) & 20 & $13.6 \pm 8.8$ & $15.4 \pm 7.8$ & $16.5 \pm 6.2$ & $3.1 \pm 2.4$ & $0.0005^{(2)}$ \\
\hline Visual perception (mean $\pm S D$ ) & 10 & $5.8 \pm 2.2$ & $2.2 \pm 3.2$ & $0.6 \pm 1.1$ & $6.1 \pm 2.3$ & $0.0001^{(3)}$ \\
\hline Auditory perception (mean $\pm S D$ ) & 11 & $7.0 \pm 4.4$ & $2.2 \pm 3.2$ & $4.1 \pm 4.8$ & $10.4 \pm 0.5$ & $0.0179^{(4)}$ \\
\hline Comprehension (mean $\pm \mathrm{SD}$ ) & 6 & $4.6 \pm 1.7$ & $3.4 \pm 2.7$ & $2.2 \pm 2.7$ & $5.6 \pm 0.9$ & $0.0167^{(4)}$ \\
\hline Word repetition (mean $\pm S D$ ) & 4 & $1.4 \pm 1.9$ & $2.0 \pm 1.9$ & $1.5 \pm 2.0$ & $4.0 \pm 0.0$ & $0.0028^{(5)}$ \\
\hline Sentence repetition (mean $\pm S D$ ) & 3 & $0.8 \pm 1.1$ & $1.2 \pm 1.6$ & $1.0 \pm 1.5$ & $2.7 \pm 1.0$ & $0.0092^{(5)}$ \\
\hline Naming (mean $\pm S D)$ & 6 & $2.2 \pm 3.0$ & $3.2 \pm 2.6$ & $1.5 \pm 2.4$ & $5.8 \pm 0.4$ & $0.0008^{(5)}$ \\
\hline Spontaneous speech* & - & 5 & 5 & 14 & 2 & $0.0001^{(6)}$ \\
\hline Counting from 1 to $20^{*}$ & - & 4 & 2 & 11 & 1 & $0.0120^{(6)}$ \\
\hline Mentioning the 7 weekdays* & - & 3 & 3 & 10 & 0 & $0.0046^{(6)}$ \\
\hline Singing* & - & 3 & 4 & 12 & 0 & $0.0001^{(6)}$ \\
\hline Phono-articulatory function* & - & 0 & 4 & 4 & 7 & $0.0043^{(6)}$ \\
\hline Constructional praxis (4 matches)* & - & 3 & 2 & 14 & 4 & $0.0021^{(6)}$ \\
\hline Constructional praxis (9 matches)* & - & 2 & 4 & 14 & 6 & $0.0105^{(6)}$ \\
\hline Ideomotor praxis (mean $\pm S D$ ) & 5 & $2.8 \pm 1.6$ & $2.4 \pm 1.5$ & $1.6 \pm 2.0$ & $4.7 \pm 0.5$ & $0.0012^{(7)}$ \\
\hline
\end{tabular}

SD: standard deviation; MCA: middle cerebral artery. *Number of subjects with difficulties and/or errors; ${ }^{(1)}$ ANOVA; ${ }^{(2)}$ ANOVA followed by Tukey's test (differences between the following groups: capsule-nuclear and whole middle cerebral artery territory; capsule-nuclear and temporal-parietal; capsulenuclear and frontal); ${ }^{(3)}$ ANOVA followed by Tukey's test (differences between the following groups: frontal and temporal-parietal; frontal and whole middle cerebral artery territory; capsule-nuclear and temporal-parietal; capsule-nuclear and whole middle cerebral artery territory); ${ }^{(4)}$ ANOVA followed by Tukey's test (differences between the capsule-nuclear group and the whole middle cerebral artery territory group); ${ }^{(5)}$ ANOVA followed by Tukey's test (differences between the following groups: capsule-nuclear and whole middle cerebral artery territory; capsule-nuclear and frontal); ${ }^{(6)}$ Fisher's exact test; ${ }^{(7)}$ ANOVA followed by Tukey's test (differences between the following groups: capsule-nuclear and temporal-parietal; capsule-nuclear and whole middle cerebral artery territory).

\section{DISCUSSION}

All tests could differentiate between patients and controls, as much as discriminate which patients showed predominant fluency impairment from those whose injuries mostly weakened comprehension. All test items were of significance for comparisons between the linguistic evaluation and the brain injury topography for stroke patients, except for age and education, as we expected, since these two parameters are not topographical predictors for brain injuries.

The time-window used for subject evaluation was appropriate, since $100 \%$ of the approached subjects could be tested within the first 72 hours post-stroke, and considering that comatose patients were not assessed. Age, schooling and handedness were similar for groups of patients and controls, with no statistically significant difference. Despite the sample size, it is likely that this pairing helped minimize the effect that schooling might have had on some tests ("A" Random Letter Test ${ }^{8}$, visual perception of abstract forms $\mathrm{s}^{10}$, auditory perception of phonemes ${ }^{11}$, constructional praxis). The size of the sample was an important limitation, though, for the inclusion of more patients might have confirmed the power of more tests with significant results for stroke localization.
Only four tests were able to predict the presence of left hemisphere lesions: word and sentence repetition, naming, and ideomotor praxis. Although not statistically significant, counting from 1 to 20 and comprehension tasks also were more impaired in patients with left hemisphere injuries. Difficulties for counting were probably due to language impairment and not to the low educational levels of our patients ${ }^{17}$, since the left hemisphere group had a lower proportion of subjects with four years or less of elementary schooling, besides having higher educational levels. Studies with larger samples might likely be able to differentiate brain injury sides from the analysis of the other items.

Proportions of aphasic syndromes were similar to those from other studies ${ }^{18-20}$, except that none of our patients met the established criteria for conduction aphasia, anomic aphasia, subcortical (non-thalamic) aphasia or isolated apraxia of speech. This could be due to the size of the sample, but also to the strict inclusion criteria leading only to first-stroke patients being recruited.

Severity of aphasia is usually associated to stroke severity ${ }^{19,20}$. Four of the eight patients who did not survive had a cardioembolic stroke, while cardioembolism was the most frequent etiology for patients with global 
aphasia (five out of eleven patients). Most patients with aphasia changed to a less disabling form of language impairment during follow-up. A non-fluent aphasia could evolve into a fluent form of aphasia, whereas expectedly the opposite never occurred ${ }^{7,19,20}$.

All but two patients with global aphasia had large lesions in the left MCA territory, for this was the lesion site that affected most language functions. On the other hand, all cases of lone cortical dysarthria were associated to lesions in the left capsule-nuclear or right MCA territory, leaving unaffected the performance on language tests. The presence of mutism in 9 of the 11 patients with global aphasia may be explained by lesions in the frontalputaminal part of the MCA territory ${ }^{1}$.

Constructional and ideomotor apraxias were mostly associated to whole MCA territory or to focal temporalparietal lesions. The left inferior parietal component of these lesions is the main responsible for these types of apraxia, though they can also be found in premotor and callosal lesions ${ }^{21}$.

Five (15.2\%) of our language-impaired cases deviated from the classic anatomy of aphasic syndromes. One explanation could be that their CT imaging underestimated the lesion extension, even though CT and/or MRI were also performed in the chronic stroke phase, when the syndrome is usually stabilized. Other authors have found even larger proportions of aphasic syndromes deviating from their classic clinical-anatomic correlations, with cases of lesions in language areas without aphasia, nonfluent aphasia with posterior lesions, or global aphasia in small and circumscribed lesions ${ }^{1,22,23}$. Besides, "localization" of aphasic syndromes to particular brain areas is a challenging task that can only be approximate, due to interindividual variability in the boundaries of cytoarchitectural fields, as well as in the patterns of sulci and gyri ${ }^{3,24}$. Moreover, the resulting syndrome should be explained not only by functional loss of the damaged area, but also by disturbances of excitation-inhibition balance along with functional reorganization in other brain regions ${ }^{25}$.

The concept of aphasias as vascular syndromes could be clinically useful ${ }^{2,3}$, since they lead to strong predictions about what parts of the brain are ischemic, even in cases when DWI does not reveal all dysfunctional areas. However, as there are cases which deviate from the classic anatomy of aphasic syndromes, a simpler, quicker and more reliable approach to lesion localization would be to evaluate tasks such as repetition of words and sentences, comprehension and naming.

In this study, impairment of repetition was found in frontal, temporal-parietal, and whole MCA territory lesions. This was expected, since misrepresented repetition usually corresponds to lesions located deeply or in the margins of the left lateral sulcus, comprising structures from the frontal-opercular to the supramarginal and superior temporal gyri, arcuate fasciculus, external capsule, posterior arm of the internal capsule, and even the thalamus ${ }^{1}$. Comprehension disorders associated to MCA and temporal-parietal strokes also attest to lesions in the posterior portions of the temporal gyri extending to the external capsule, and less frequently to frontal and inferior parietal lesions (in these two latter locations when sentences with complex logical-grammatical structures like "bigger than", or "father's brother", are used). The object naming task could predict lesions in the dominant (left) hemisphere, but this task is considered to have low power for hemispheric localization, since object or picture naming require many different cognitive representations and processes, which engage distinct and partly overlapping brain regions from the anterior to the posterior cortex, or subcortical regions including the thalamus $^{3}$. In regard to impairments in spontaneous speech and fluency, particularly the presence of mutism, our findings also concur with those of the medical literature $^{24}$, indicating more anterior extensions of the lesions.

Besides sample size and variety, another limitation of this study was that 20 (of 37 patients) underwent cerebral CT but not MRI. Further studies should use DWI and T2-MRI in the hyperacute stroke phase (within the first hours from onset) to determine infarct size, as well as during follow-up, in order to verify the dynamics of penumbra regions in function-specific brain areas for more precise brain-language-behavioral correlations and stroke management.

Despite these limitations, we can conclude that tasks of word and sentence repetition, comprehension, naming, analysis of spontaneous speech and fluency, and ideomotor praxis used in this study can help neurologists to determine side and location of lesions in the acute stroke phase, while impairments in all these tasks may indicate larger lesions in the MCA territory.

ACKNOWLEDGMENTS - We acknowledge the help of the Statistics section of the Research Chamber, Faculty of Medical Sciences, University of Campinas / UNICAMP. We are also indebted to our patients and their families for kindly agreeing to participate on the study.

\section{REFERENCES}

1. Kreisler A, Godefroy O, Delmaire C, et al. The anatomy of aphasia revisited. Neurology 2000;54:1117-1123

2. Oliveira FF, Avelar WM, Bichuetti DB, et al. Semantic aphasia as a sole manifestation of acute stroke. Arq Neuropsiquiatr 2010;68:965-967.

3. Hillis AE. Aphasia: Progress in the last quarter of a century. Neurology 2007;69:200-213.

4. Lezak MD, Howieson DB, Loring DW. Neuropsychological Assessment. $4^{\text {th }}$ edition. New York: Oxford University Press, 2004.

5. Hand PJ, Haisma JA, Kwan J, et al. Interobserver agreement for the bedside clinical assessment of suspected stroke. Stroke 2006;37:776-780.

6. WHO MONICA Project Principle Investigators. The World Health Organization MONICA Project (monitoring trends and determinants in cardio- 
vascular disease): a major international collaboration. J Clin Epidemiol 1988:41:105-114

7. Oliveira FF, Damasceno BP. Short-term prognosis for speech and language in first stroke patients. Arq Neuropsiquiatr 2009;67:849-855.

8. Strub RL, Black FW. The mental status examination in neurology. $4^{\text {th }}$ edition. Philadelphia: Davis, 2000.

9. Oldfield RC. The assessment and analysis of handedness. The Edinburgh Inventory. Neuropsychologia 1971;9:97-113.

10. Jones-Gotman M, Zatorre RJ, Olivier A, et al. Learning and retention of words and designs following excision from medial or lateral temporallobe structures. Neuropsychologia 1997:35:963-973.

11. Christensen AL. Luria's neuropsychological investigation. $2^{\text {nd }}$ edition. Copenhagen: Munksgaard, 1979

12. Kertesz A, Ferro JM, Shewan CM. Apraxia and aphasia: the functional-anatomical basis for their dissociation. Neurology 1984;34:40-47.

13. Benson DF. Aphasia. In: Heilman KM, Valenstein E (Org). Clinical neuropsychology. $3^{\text {rd }}$ edition. New York: Oxford University Press, 1993.

14. Ogar J, Willock S, Baldo J, Wilkins D, Ludy C, Dronkers N. Clinical and anatomical correlates of apraxia of speech. Brain Lang 2006;97:343-350.

15. Adams HP, Bendixen BH, Kappelle LJ, et al. Classification of subtype of acute ischemic stroke: definitions for use in a multicenter clinical trial. Stroke 1993;24:35-41.
16. Radanovic M, Scaff M. Speech and language disturbances due to subcortical lesions. Brain Lang 2003;84:337-352.

17. Soares ECS, Ortiz KZ. Influence of schooling on language abilities of adults without linguistic disorders. Sao Paulo Med J 2009;127:134-139.

18. Godefroy O, Dubois C, Debachy B, Leclerc M, Kreisler A. Vascular aphasias: main characteristics of patients hospitalized in acute stroke units. Stroke 2002;33:702-705.

19. Laska AC, Hellblom A, Murray V, Kahan T, von Arbin M. Aphasia in acute stroke and relation to outcome. J Intern Med 2001;249:413-422.

20. Pedersen PM, Vinter K, Olsen TS. Aphasia after stroke: type, severity and prognosis. The Copenhagen aphasia study. Cerebrovasc Dis 2004; 17:35-43.

21. Wheaton LA, Hallett M. Ideomotor apraxia: a review. J Neurol Sci 2007; 260:1-10

22. Basso A, Lecours AR, Moraschini S, Vanier M. Anatomoclinical correlations of the aphasias as defined through computerized tomography: exceptions. Brain Lang 1985:26:201-229.

23. Willmes K, Poeck K. To what extent can aphasic syndromes be localized? Brain 1993;116:1527-1540.

24. Mohr JP, Pessin MS, Finkelstein S, Funkenstein HH, Duncan GW, Davis KR. Broca aphasia: pathologic and clinical. Neurology 1978;28:311-324.

25. Fuster JM. The prefrontal cortex. $4^{\text {th }}$ edition. London: Elsevier, 2008. 